\title{
1,4-Disubstituted-1,2,3-Triazole Compounds Induce Ultrastructural Alterations in Leishmania amazonensis Promastigote: An in Vitro Antileishmanial and in Silico Pharmacokinetic Study
}

\author{
Fernando Almeida-Souza ${ }^{1,2, * \mathbb{D}}$, Verônica Diniz da Silva ${ }^{3,4}$, Gabriel Xavier Silva ${ }^{5}$, \\ Noemi Nosomi Taniwaki ${ }^{6}$, Daiana de Jesus Hardoim ${ }^{2}$, Camilla Djenne Buarque ${ }^{3}$, \\ Ana Lucia Abreu-Silva ${ }^{1, *,+} \mathbb{D}$ and Kátia da Silva Calabrese ${ }^{2,+}$ \\ 1 Pós-graduação em Ciência Animal, Universidade Estadual do Maranhão, São Luís 65055-310, Brazil \\ 2 Laboratório de Imunomodulação e Protozoologia, Instituto Oswaldo Cruz, Fiocruz, Rio de Janeiro 21040-900, \\ Brazil; daianahardoim@gmail.com (D.d.J.H.); calabrese@ioc.fiocruz.br (K.d.S.C.) \\ 3 Laboratório de Síntese Orgânica, Pontifícia Universidade Católica, Rio de Janeiro 22451-900, Brazil; \\ veronk.d1niz@gmail.com (V.D.d.S.); camilla.buarque@gmail.com (C.D.B.) \\ 4 Faculdade de Ciência e Tecnologia, Universidade Nova de Lisboa, 2825-149 Caparica, Portugal \\ 5 Rede Nordeste de Biotecnologia, Universidade Federal do Maranhão, São Luís 65080-805, Brazil; \\ xaviersilva.g@gmail.com \\ 6 Núcleo de Microscopia Eletrônica, Instituto Adolfo Lutz, São Paulo 01246-000, Brazil; \\ noemi.taniwaki@ial.sp.gov.br \\ * Correspondence: fernandoalsouza@gmail.com (F.A.-S.); abreusilva.ana@gmail.com (A.L.A.-S.) \\ + These authors equally contributed to this work.
}

Received: 26 June 2020; Accepted: 14 July 2020; Published: 18 September 2020

\begin{abstract}
The current standard treatment for leishmaniasis has remained the same for over 100 years, despite inducing several adverse effects and increasing cases of resistance. In this study we evaluated the in vitro antileishmanial activity of 1,4-disubstituted-1,2,3 triazole compounds and carried out in silico predictive study of their pharmacokinetic and toxicity properties. Ten compounds were analyzed, with compound 6 notably presenting $\mathrm{IC}_{50}: 14.64 \pm 4.392 \mu \mathrm{M}$ against promastigotes, $\mathrm{IC}_{50}: 17.78 \pm 3.257 \mu \mathrm{M}$ against intracellular amastigotes, $\mathrm{CC}_{50}: 547.88 \pm 3.256 \mu \mathrm{M}$ against $\mathrm{BALB} / \mathrm{C}$ peritoneal macrophages, and 30.81-fold selectivity for the parasite over the cells. It also resulted in a remarkable decrease in all the parameters of in vitro infection. Ultrastructural analysis revealed lipid corpuscles, a nucleus with discontinuity of the nuclear membrane, a change in nuclear chromatin, and kinetoplast swelling with breakdown of the mitochondrial cristae and electron-density loss induced by 1,4-disubstituted-1,2,3-triazole treatment. In addition, compound 6 enhanced 2.3-fold the nitrite levels in the Leishmania-stimulated macrophages. In silico pharmacokinetic prediction of compound 6 revealed that it is not recommended for topical formulation cutaneous leishmaniasis treatment, however the other properties exhibited results that were similar or even better than miltefosine, making it a good candidate for further in vivo studies against Leishmania parasites.
\end{abstract}

Keywords: cytotoxicity; transmission electron microscopy; leishmaniasis; treatment; ADME; toxicity

\section{Introduction}

Leishmaniasis is a complex of infectious diseases caused by protozoa of the Leishmania genus. It is transmitted through the bite of female sandflies, and its clinical manifestations include cutaneous, mucosal and visceral forms, with the third presenting considerable rates of morbidity and mortality $[1,2]$. Even today, it continues one of the most important global parasitic diseases, affecting millions of 
people, especially in developing countries [3]. The World Health Organization (WHO) estimates there are 12 million cases of visceral leishmaniasis worldwide, with 300,000 new cases and more than 20,000 deaths per year, while there have been 1 million new cases of cutaneous leishmaniasis reported in the last five years. More than 1 billion people live at risk of infection, and $90 \%$ of registered cases of leishmaniasis occur in developing countries [4].

The current treatment is still based on pentavalent antimonials, which have been in use since 1912, and like the other drugs used in leishmaniasis treatment, such as amphotericin B, pentamidine and miltefosine, induce several adverse drug effects [5-8]. In general, treatment is expensive and (with the exception of miltefosine, which is administrated orally) causes discomfort to patients due to parenteral administration for prolonged periods. These characteristics, associated with the increasing number of cases of resistance to current treatments, immunosuppressed patients (HIV coinfections and malnourished individuals, for example) and those with hepatic and renal disorders, showing the necessity for research into new therapy options that are more efficient and non-toxic $[9,10]$.

Triazoles are important heterocycles of synthetic origin involved in several industrial applications, such as agrochemistry, material sciences, and the synthesis of new drugs [11,12]. 1,2,3-triazole is an important pharmacophoric group present in several heterocyclic compounds [13], and covers a wide range of biological applications, such as anti-tubercular [14], antimicrobial [15], anticonvulsant [16], antiviral [17], and anticancer [18] activities, among others. It can be obtained by several synthetic routes; however, the click chemistry reaction, also known as copper-catalyzed alkyne-azide cycloaddition, is a powerful tool in chemical medicine for the supply of highly versatile 1,2,3-triazole scaffolds due to its simplicity, robustness, and applicability $[11,19,20]$.

The triazole compound family is also known for its potential activity against fungi [21] and trypanosomatids, such as parasites of the genus Leishmania [22,23]. We recently carried out the design, synthesis, and structural characterization of new 1,4-disubstituted-1,2,3-triazole compounds by copper-catalyzed azide-alkyne click chemistry reaction [24]; however, its antileishmanial potential has not yet been elucidated. Triazole compounds were planned to correlate the effect of the exchange of functional groups of aldehydes by classical privileged groups such as sulphonylhydrazones, hydrazones, and coumarin with anticancer and antileishmanial activity [24-26]. These groups can also act in synergism with the 1,2,3-triazole nucleus and potentiate the pharmacological activity. The triazole group has interesting physical-chemical and chemical properties that can mimic the characteristics of different functional groups $[13,24]$.

In the present study, we evaluated the in vitro antileishmanial activity of the 1,4-disubstituted-1,2,3-triazole compounds, demonstrating the ultrastructural alterations the treatment induced in Leishmania amazonensis promastigotes. In addition, we performed an in silico predictive study of the drug-likeness, pharmacokinetics properties, and toxicity of the triazole compounds that exhibited the best antileishmanial activity.

\section{Results}

\subsection{Activity of 1,4-Disubstituted-1,2,3-Triazole against L. amazonensis Promastigote and Intracellular Amastigote Forms}

The $\mathrm{IC}_{50}$ results of the activity against promastigote and intracellular amastigote forms of the 1,4-disubstituted-1,2,3-triazole compounds (Figure 1) are shown in Table 1. The trial assay against L. amazonensis promastigote revealed that compounds $\mathbf{2}$ and $\mathbf{5}$ demonstrated greater activity, with $50 \%$ inhibitory concentration $\left(\mathrm{IC}_{50}\right)$ values below $10 \mu \mathrm{M}$. Compounds 4 and $\mathbf{6}$ presented intermediate activity, with $\mathrm{IC}_{50}$ around $15 \mu \mathrm{M}$. The other compounds, 1, 3, and 7, presented activity above $50 \mu \mathrm{M}$ or did not exhibit any such activity even at the maximum analyzed concentration, such as compounds 8 , 9, and 10. 
<smiles>O=Cc1ccccc1-n1cc(COc2ccccc2)nn1</smiles><smiles>O=Cc1ccccc1-n1cc(COc2cccc(OCc3cn(-c4ccccc4C=O)nn3)c2)nn1</smiles>

2<smiles>C#CCOc1cccc(OCc2cn(-c3ccccc3C=O)nn2)c1</smiles><smiles>Cc1ccc(S(=O)(=O)NN)cc1</smiles><smiles>N=Cc1ccccc1-n1cc(COc2ccccc2)nn1</smiles><smiles>O=Cc1ccccc1-n1cc(-c2ccccc2)nn1</smiles><smiles>OCc1ccccc1-n1cc(COc2ccccc2)nn1</smiles><smiles>O=Cc1ccccc1-n1cc(COc2cccc(O)c2)nn1</smiles><smiles>C(=N/Nc1ccccc1)\c1ccccc1-n1cc(COc2ccccc2)nn1</smiles><smiles>O=c1ccc2cc(-n3cc(COc4ccccc4)nn3)ccc2o1</smiles><smiles>O=S(=O)([Al])N/N=C/c1ccccc1-n1cc(COc2cccc(OCc3cn(-c4ccccc4/C=N/NS(=O)(=O)[Al])nn3)c2)nn1</smiles>

Figure 1. Chemical structure of the 1,4-disubstituted-1,2,3-triazoles derivatives analyzed.

Table 1. Activity against promastigotes and intracellular amastigotes of Leishmania amazonensis, cytotoxicity in BALB/c peritoneal macrophages, and selectivity index after $24 \mathrm{~h}$ of treatment with 1,4-disubstituted-1,2,3-triazole compounds.

\begin{tabular}{ccccc}
\hline \multirow{2}{*}{ Compounds } & \multicolumn{2}{c}{$\mathrm{IC}_{\mathbf{5 0}}(\boldsymbol{\mu M})$} & \multirow{2}{*}{$\mathrm{CC}_{\mathbf{5 0}}(\boldsymbol{\mu M})$} & \multirow{2}{*}{ SI } \\
\cline { 2 - 3 } & Promastigote & Intracellular Amastigote & & \\
\hline $\mathbf{1}$ & $53.70 \pm 8.467$ & - & $221.20 \pm 4.824$ & - \\
$\mathbf{2}$ & $\mathbf{8 . 8 5} \pm \mathbf{3 . 4 3 6}$ & $37.92 \pm 3.350$ & $248.46 \pm 2.519$ & 6.55 \\
$\mathbf{3}$ & $50.93 \pm 4.571$ & - & $307.73 \pm 4.071$ & - \\
$\mathbf{4}$ & $\mathbf{1 5 . 6 8} \pm \mathbf{5 . 4 1 8}$ & $149.8 \pm 6.367$ & $144.80 \pm 4.100$ & 0.96 \\
$\mathbf{5}$ & $\mathbf{8 . 8 1} \pm \mathbf{3 . 9 3 3}$ & $32.31 \pm 2.256$ & $58.01 \pm 2.647$ & 1.79 \\
$\mathbf{6}$ & $\mathbf{1 4 . 6 4} \pm \mathbf{4 . 3 9 2}$ & $\mathbf{1 7 . 7 8} \pm \mathbf{3 . 2 5 7}$ & $547.88 \pm 3.256$ & $\mathbf{3 0 . 8 1}$ \\
$\mathbf{7}$ & $62.98 \pm 5.878$ & - & $412.00 \pm 4.917$ & - \\
$\mathbf{8}$ & $>300$ & - & $>600$ & - \\
$\mathbf{9}$ & $>300$ & - & $>600$ & - \\
$\mathbf{1 0}$ & $>300$ & - & $>600$ & - \\
Miltefosine & $8.56 \pm 0.695$ & $11.615 \pm 1.790$ & $152.61 \pm 3.855$ & 13.13 \\
\hline
\end{tabular}

$\mathrm{IC}_{50}$ : inhibitory concentration of $50 \%$ parasites. $\mathrm{CC}_{50}$ : cytotoxicity concentration of $50 \%$ cells. SI: selectivity index calculated from the ratio of $\mathrm{CC}_{50}$ versus the $\mathrm{IC}_{50}$ for intracellular amastigotes. -: not determined. Data represent mean \pm standard deviation of three experiments performed at least in triplicate.

The compounds that exhibited greater (2 and 5) and intermediate activity (4 and 6) against promastigote forms were selected for evaluation against the intracellular amastigote. Compound 6 exhibited the lowest $\mathrm{IC}_{50}$, maintaining an active concentration similar to that obtained against the promastigote form. Compounds 2 and 5, which had the best result against promastigotes, showed a more than four-fold increase in $\mathrm{IC}_{50}$ value against intracellular amastigote forms when compared to their $\mathrm{IC}_{50}$ values against promastigotes. Compound 4 had the worst activity among the compounds evaluated against intracellular amastigote, with a 9.5-fold increase in $\mathrm{IC}_{50}$ value compared to the 
promastigote forms. The decrease in intracellular amastigotes can be visually observed in the light microscopy images (Figure 2).

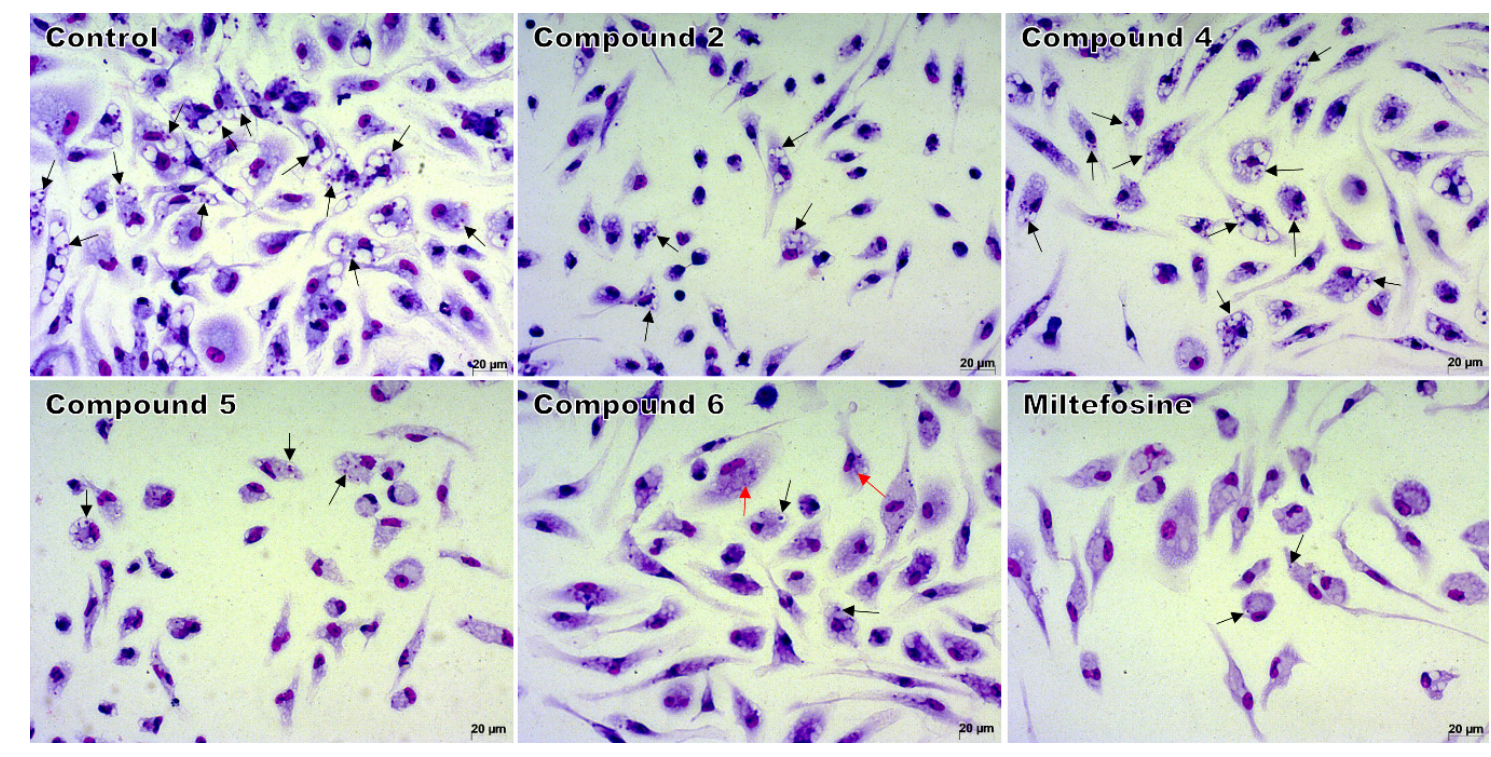

Figure 2. Light microscopy of macrophages infected and treated with 1,4-disubstituted-1,2,3-triazole compounds 2,4 , or 5 at $37.5 \mu \mathrm{M}$; with compound 6 at $18.7 \mu \mathrm{M}$; or with miltefosine at $25 \mu \mathrm{M}$. Intracellular amastigotes (black arrows) and remains of amastigotes (red arrows) inside macrophages. Giemsa, $40 \times$ objective. The images are representative of two independent experiments performed in quadruplicate.

The comparison of the parameters of infection of the treated infected cells with untreated infected cells (Figure $3 \mathrm{~A}-\mathrm{O}$ ) corroborates the activity against intracellular amastigote results. Compound 4 statistically decreased the number of amastigotes per 200 cells $(p=0.0481$, Figure 3D) at $37.5 \mu \mathrm{M}$ only, and did not significantly alter the other parameters of infection at any of the concentrations evaluated. Compound 2 decreased the number of amastigotes per 200 cells ( $p=0.0193$, Figure 3A) and amastigotes per infected cell $(p=0.0102$, Figure $3 \mathrm{C})$ at $37.5 \mu \mathrm{M}$, whereas compound 5 reduced all the three parameters of infection at $37.5 \mu \mathrm{M}$, especially the number of amastigotes per 200 cells $(p=0.0065$, Figure 3G) and amastigotes per infected cell ( $p=0.0070$, Figure 3I). Compound 6 altered all the three parameters of infection at $37.5 \mu \mathrm{M}$ with a remarkable reduction in the number of amastigotes per 200 cells ( $p=0.0028$, Figure 3J) and was still able to reduce the number of amastigotes per 200 cells $(p=0.0375$, Figure $3 \mathrm{~J})$ and amastigotes per infected cell $(p=0.0333$, Figure $3 \mathrm{~L})$ at $18.7 \mu \mathrm{M}$, demonstrating the best activity of the compounds analyzed. Miltefosine exhibited reduction of all three parameters of infection at 25 and $12.5 \mu \mathrm{M}(p=0.0024$ and $p=0.0123$, Figure $3 \mathrm{M} ; p=0.0013$ and $p=0.0313$, Figure $3 \mathrm{~N}$; $p=0.0036$ and $p=0.0321$, Figure 3O).

\subsection{Cytotoxicity and Selectivity Index (SI) of 1,4-Disubstituted-1,2,3-Triazole Compounds}

Compound 5 presented the highest cytotoxicity among the tested compounds, with all the other compounds exhibiting $\mathrm{CC}_{50}$ values above $100 \mu \mathrm{M}$. Compound 4 showed the lowest SI value among the analyzed compounds due to low activity against the intracellular amastigotes, and was more toxic to the cell than to the intracellular amastigote. Compound $\mathbf{6}$ exhibited the lowest cytotoxicity among the analyzed compounds and, as well as having the best activity against intracellular amastigotes, resulted in the highest SI-higher even than miltefosine (Table 1). 

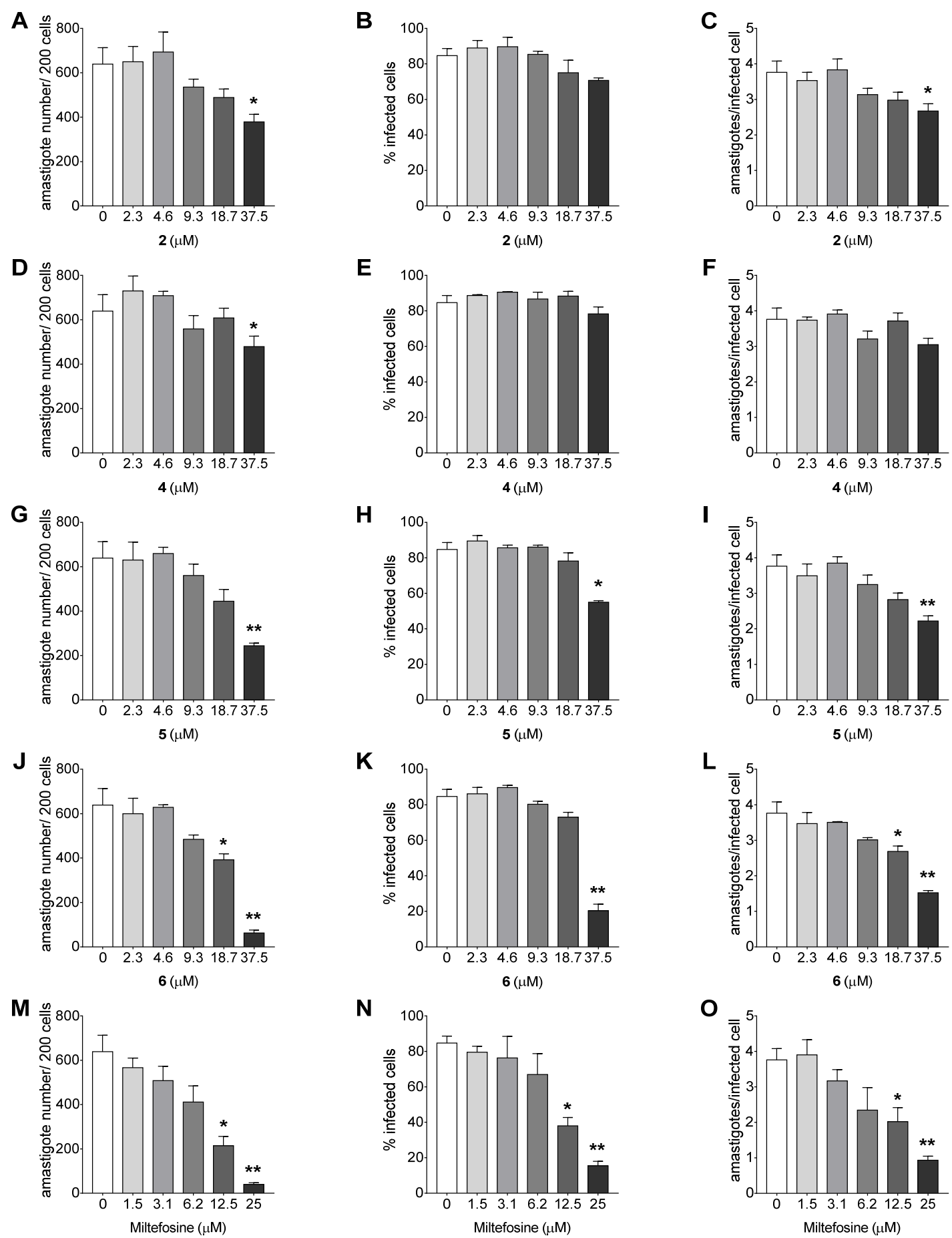

Figure 3. Activity of 1,4-disubstituted-1,2,3-triazole compounds against Leishmania amazonensis intracellular amastigotes. Parameters of infection of BALB/c peritoneal macrophages infected with L. amazonensis and treated with triazole compounds (A-L) or mltefosine (M-O) for $24 \mathrm{~h}$. The data represent mean \pm standard deviation of two independent experiments performed in quadruplicate. ${ }^{*} p<0.05$ and ${ }^{* *} p<0.01$ when compared with the control group by Kruskal-Wallis followed by Dunn's multiple comparisons test.

2.3. Ultrastructural Alterations in L. amazonensis Promastigotes Treated with 1,4-Disubstituted-1,2,3-Triazole Compounds

Transmission electron microscopy was performed with the compounds that presented the best activity against promastigotes, namely compounds 2, 4, 5, and 6, based on $\mathrm{IC}_{50}$. No changes 
were observed in the nucleus, mitochondria, flagellum, kinetoplast, or any other organelle in parasites without treatment, which displayed normal morphology (Figure 4A). All four compounds induced ultrastructural alterations in the promastigote forms of L. amazonensis after $24 \mathrm{~h}$ of treatment. Parasites treated with compound 4 presented swelling of the kinetoplast and a change in chromatin distribution (Figure 4B). Compound 2 induced an increase in lipid corpuscles (white arrows), electron dense vesicles inside small vacuoles in the cytoplasm (thin arrow) (Figure 5A) or free vesicles with electron-dense material in the cytoplasm (thin arrows) and small vacuoles near the flagellar pocket (black arrows) (Figure 5B,C). Parasites treated with compound 5 exhibited lipid corpuscles (white arrows) (Figure 6A), extension of the kinetoplast containing granular material (white asterisk) (Figure 6B) or a swollen kinetoplast (white asterisk) as well as swollen mitochondria with deranged cristae (Figure 6C), vacuoles containing filamentous material (black asterisks) (Figure 6B,C), a flagellar pocket with electron dense material in a circular or rod shape (short thin arrow), and vesicles near the flagellar pocket (thin arrow) (Figure 6C), undefined nuclear membrane (Figure 6B,C) and nuclei with altered chromatin distribution (Figure 6A-C). Compound 6, as well as inducing lipid corpuscles (white arrows) (Figure 7A), large vacuoles containing electron-dense material (black asterisks) (Figure 7A,B), and swollen mitochondria with degenerated regions (Figure 7B), also exhibited a parasite in the degeneration stage, a trace of kinetoplast with electron-density loss (white asterisks) and nuclear alterations, such as the discontinuity of the nuclear membrane and pyknotic chromatin (arrowhead), and the loss of cytoplasm organelles, highlighting its antileishmanial potential (Figure 7C).

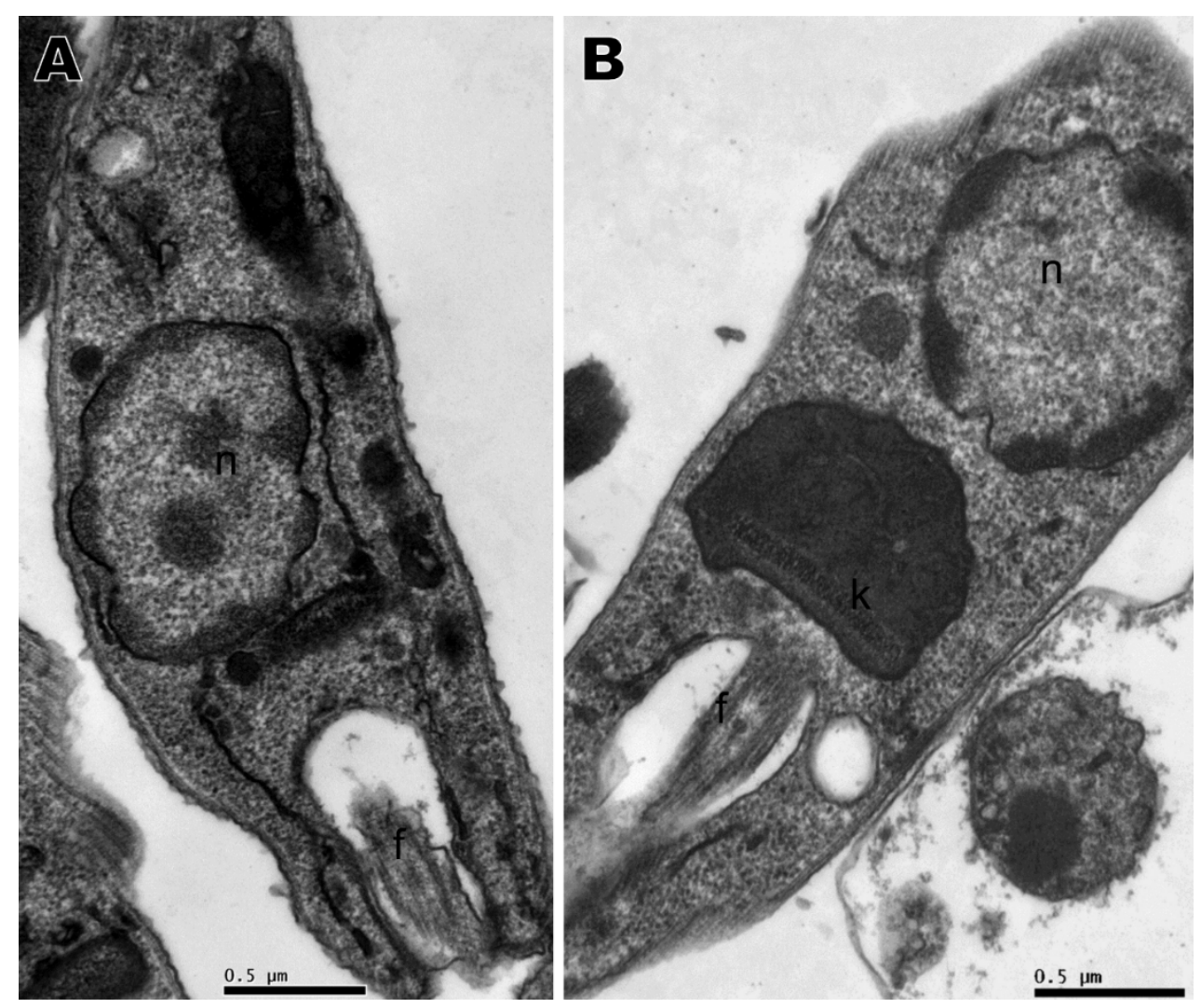

Figure 4. Transmission electron microscopy of Leishmania amazonensis promastigotes. (A) Untreated parasites. (B) Parasites treated for $24 \mathrm{~h}$ with 1,4-disubstituted-1,2,3-triazole 4 at $15.68 \mu \mathrm{M}$ presenting kinetoplast swelling and a change in chromatin distribution. $\mathrm{n}$ : nucleus, f: flagellum, k: kinetoplast. 

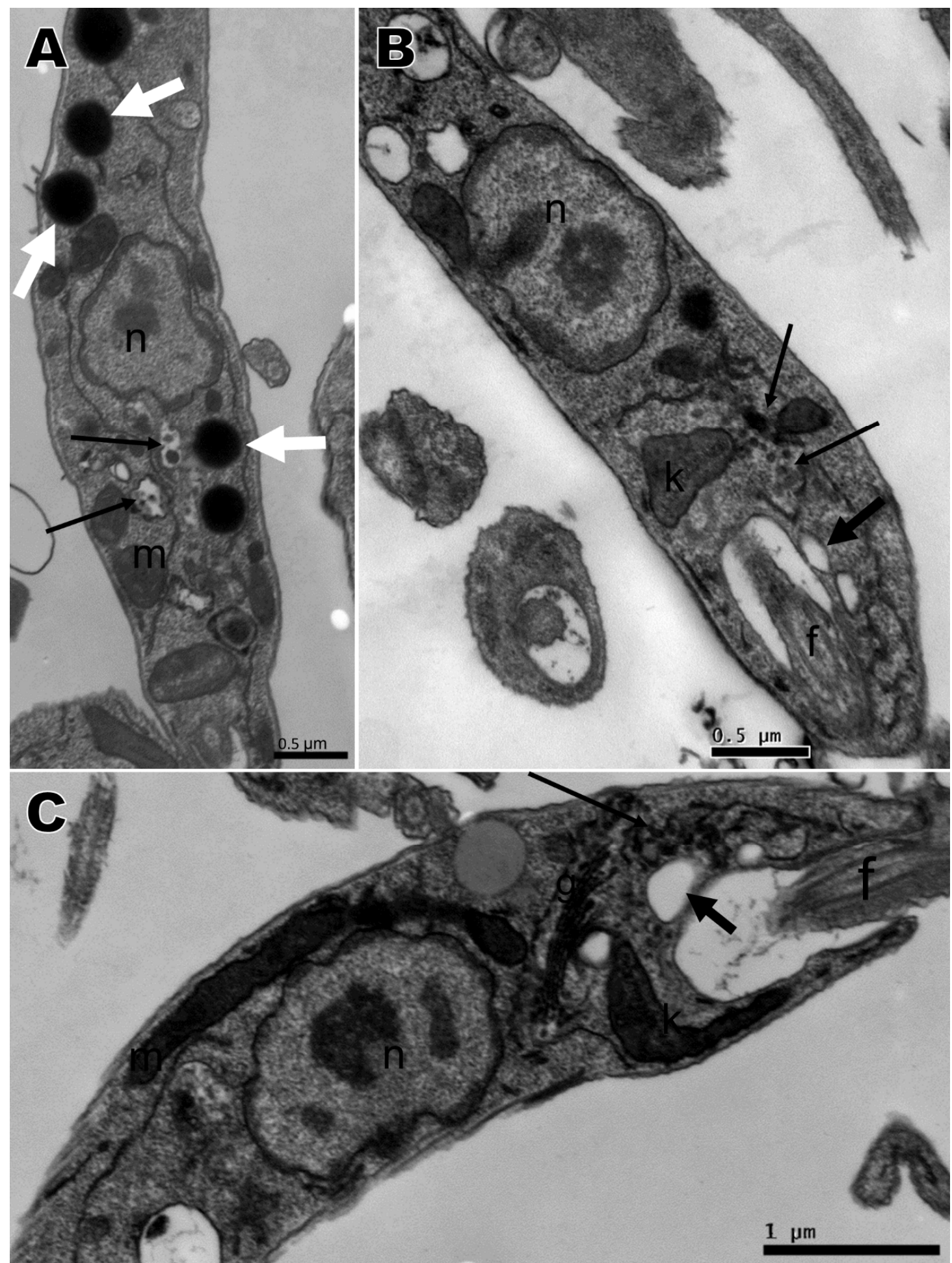

Figure 5. Ultrastructural alterations of Leishmania amazonensis promastigote forms treated for $24 \mathrm{~h}$ with 1,4-disubstituted-1,2,3-triazole 2 at $8.85 \mu \mathrm{M}$. (A-C) Lipid corpuscles (white arrows), an electron-dense vesicles free or within vacuoles in the cytoplasm (thin arrows), and small vacuoles near the flagellar pocket (black arrows). n: nucleus, m: mitochondria, k: kinetoplast, f: flagellum. 

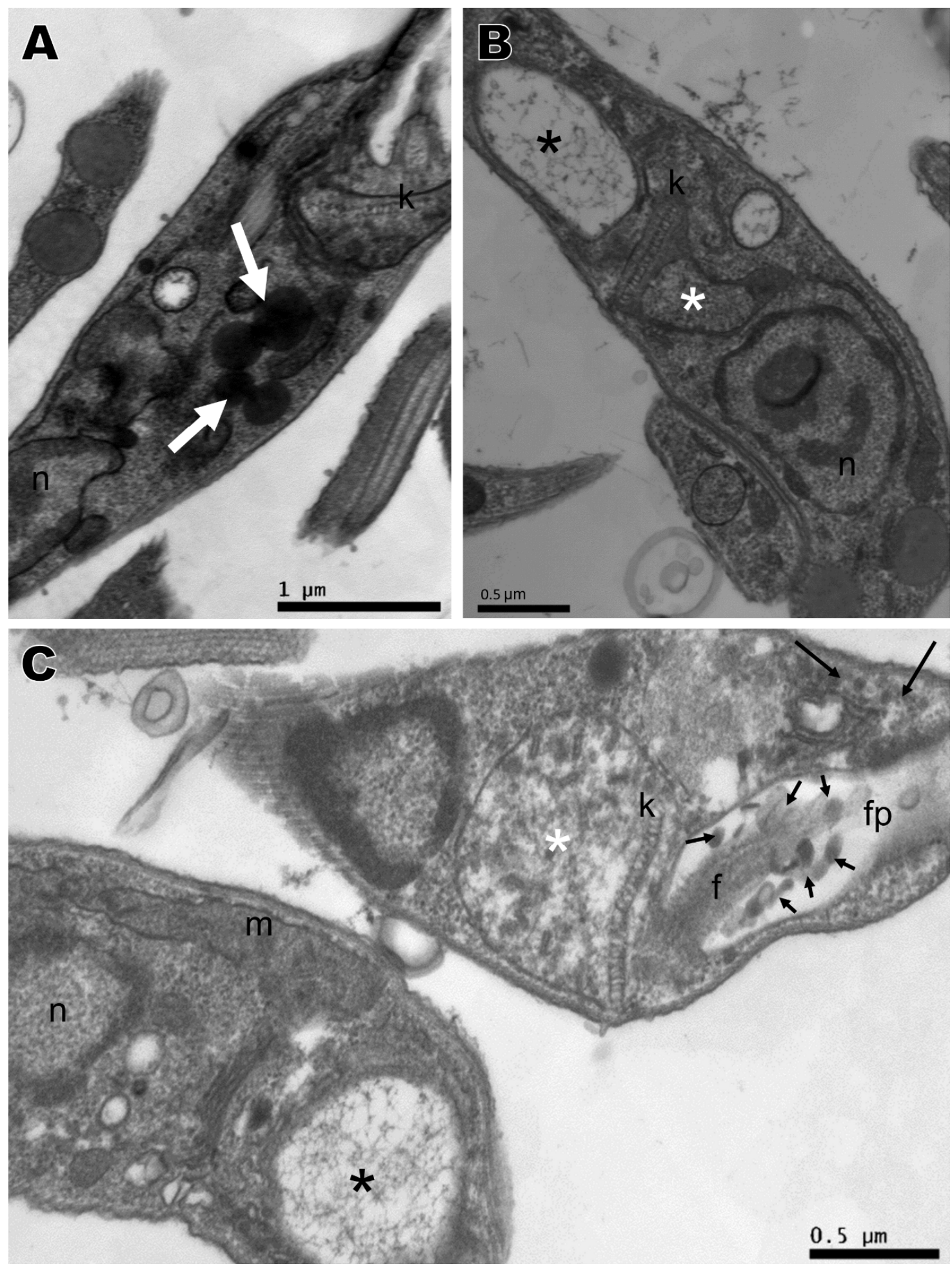

Figure 6. Ultrastructural alterations of Leishmania amazonensis promastigote forms treated for $24 \mathrm{~h}$ with 1,4-disubstituted-1,2,3-triazole 5 at $8.81 \mu \mathrm{M}$. (A-C) Lipid corpuscles (white arrows), filamentous electron-dense material within the vacuole (black asterisks), kinetoplast swelling with breakdown of mitochondrial cristae (white asterisks), and electron-dense material within the flagellar pocket (short thin arrows). k: kinetoplast, n: nucleus, f: flagellum, fp: flagellar pocket, m: mitochondria. 

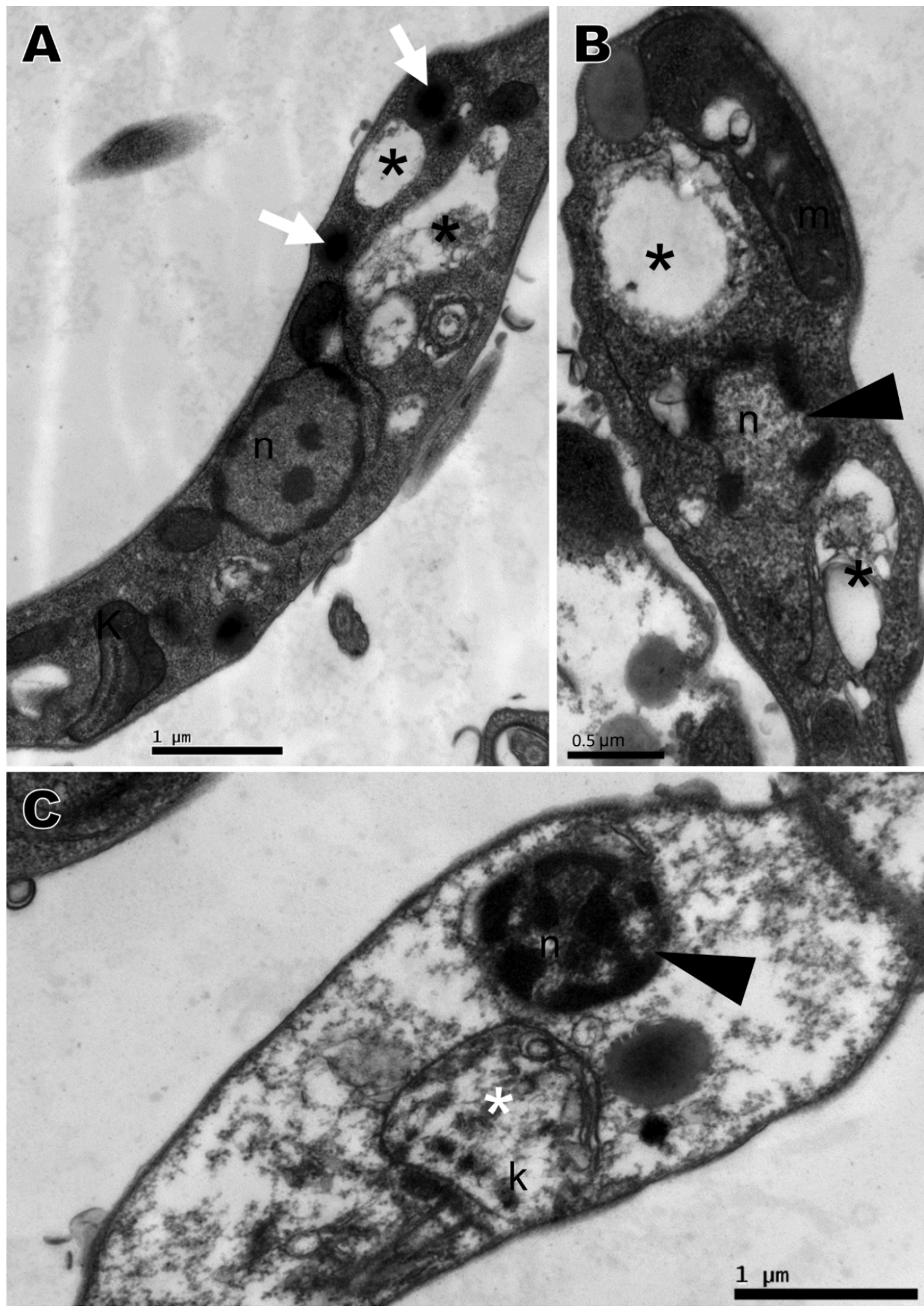

Figure 7. Ultrastructural alterations of Leishmania amazonensis promastigote forms treated for $24 \mathrm{~h}$ with 1,4-disubstituted-1,2,3-triazole 6 at $14.64 \mu \mathrm{M}$. (A-C) Lipid corpuscles (white arrows), large vacuoles containing electron-dense material (black asterisks), nucleus with discontinued nuclear membrane and change in the nuclear chromatin (arrowhead), and trace of kinetoplast with electron-density loss (white asterisks), loss in cytoplasm organelles. n: nucleus, k: kinetoplast, m: mitochondria. 


\subsection{Nitrite Quantification in Supernatant of Peritoneal Macrophages Treated with 1,4-Disubstituted-1,2,3-Triazole Compounds}

As shown in Figure 8, only BALB/c peritoneal macrophages stimulated with L. amazonensis and treated with compound 6 exhibited high nitrite levels when compared to untreated and stimulated macrophages. The nitrite level was 2.3 fold higher in macrophages stimulated and treated with compound 6 than in untreated infected macrophages.

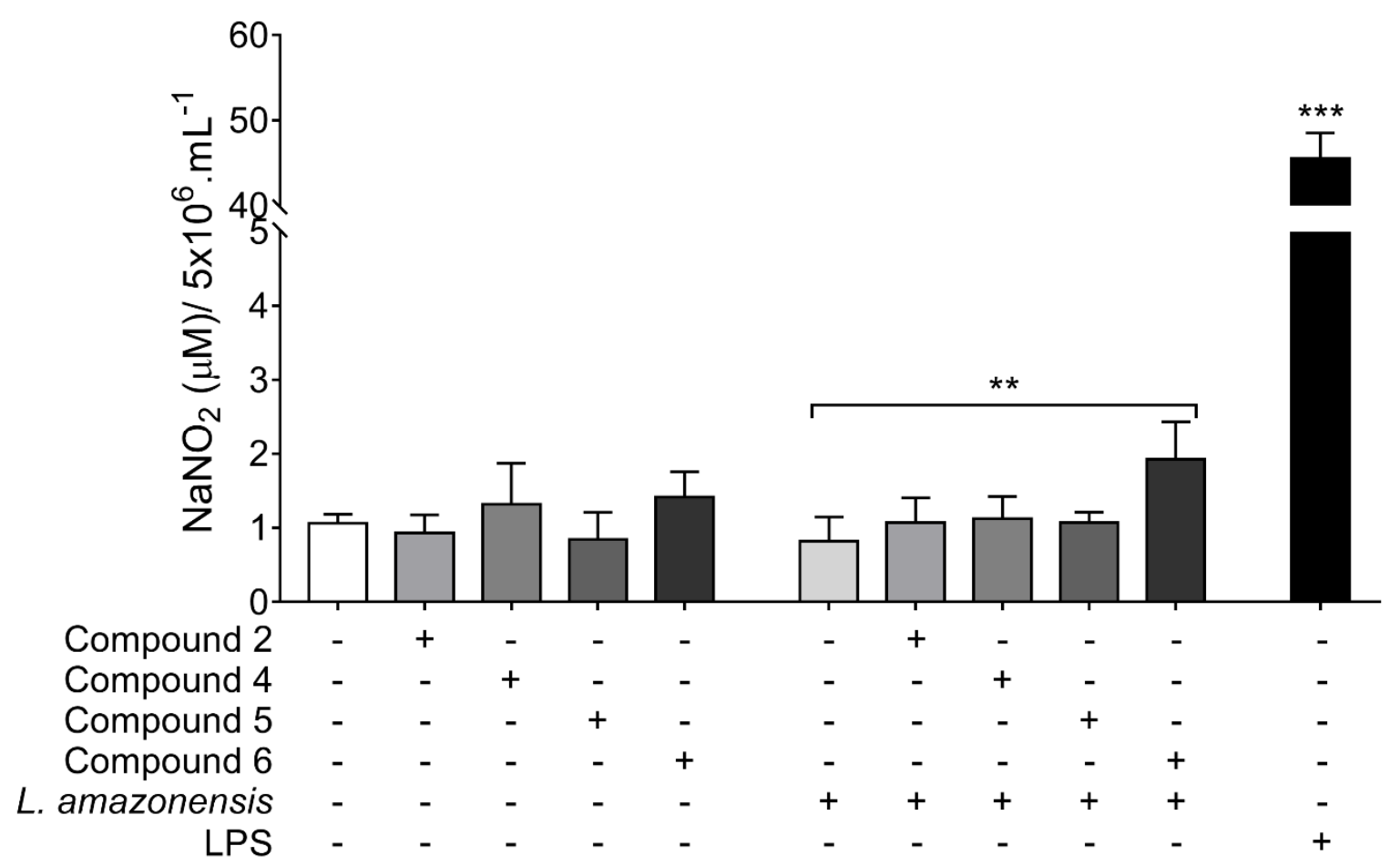

Figure 8. Nitrite quantification in supernatant of BALB/c peritoneal macrophages treated with 1,4-disubstituted-1,2,3-triazole compounds. Cells are stimulated (or not stimulated) with Leishmania amazonensis and treated for $48 \mathrm{~h}$ with compound 2,4 , or 5 at $37.5 \mu \mathrm{M}$, or with compound 6 at $18.7 \mu \mathrm{M}$. Data represents mean \pm SD of at least three independent experiments realized at least in quadruplicate. ${ }^{* *} p=0.0039,{ }^{* * *} p=0.0001$ when compared to untreated and non-infected cells, or between brackets by Kruskal-Wallis followed by Dunn's multiple comparisons test.

\subsection{In Silico Drug-Likeness Prediction}

In silico drug-likeness predictions were performed with compounds $\mathbf{2 , 4} \mathbf{5}$, and $\mathbf{6}$, which presented the best antileishmanial activity. Table 2 depicts the physicochemical, drug-likeness, and medicinal chemistry properties for 1,4-disubstituted-1,2,3-triazole compounds and miltefosine, the only available drug against leishmaniasis that is administered orally. The physicochemical characteristics of the topological polar surface area (TPSA) and lipophilicity of compound $\mathbf{6}$ were similar to miltefosine. The other compounds exhibited high polarity, except for compound 4, and lipophilicity inferior to compound 6. The drug-likeliness rules, such as the Lipinski rule of five and the Veber Ghose, Muegge, and Egan rules, were applied to the compounds. From the data, almost all the compounds obeyed the rules, with the exception of compound 2 in the Ghose rule, due to its high molecular weight. In medicinal chemistry property prediction, two complementary pattern recognition methods were used which allow the identification of potentially problematic fragments: pan-assay interference compounds (PAINS); and Brenk filters. None of the compounds created an alert by the PAINS evaluation, but all presented at least one problematic moiety by Brenk analysis. The lead-likeness criteria, which predicts if a molecular entity is suitable for optimization, identified only compound $\mathbf{2}$ as a good lead compound. On the other hand, the low value of synthetic accessibility indicates that all 
four compounds could be easily synthesized. These results indicate that 1,4-disubstituted-1,2,3-triazole compounds have drug-like properties.

Table 2. Predicted physicochemical, drug-likeness, and medicinal chemistry properties for 1,4-disubstituted-1,2,3-triazole compounds and miltefosine.

\begin{tabular}{|c|c|c|c|c|c|}
\hline \multirow{2}{*}{ Property/Model Name } & \multicolumn{5}{|c|}{ Compounds } \\
\hline & 2 & 4 & 5 & 6 & Miltefosine \\
\hline \multicolumn{6}{|l|}{ Physicochemical } \\
\hline Molecular Weight & 480.484 & 333.347 & 447.52 & 369.429 & 407.576 \\
\hline \# Rotatable bonds & 10 & 7 & 8 & 7 & 20 \\
\hline \# H-bond acceptors & 8 & 5 & 6 & 4 & 4 \\
\hline \# H-bond donors & 0 & 0 & 1 & 1 & 0 \\
\hline Surface Area & 205.260 & 144.553 & 185.782 & 162.657 & 168.579 \\
\hline $\operatorname{TPSA}\left(\AA^{2}\right)$ & 114.02 & 66.24 & 106.85 & 64.33 & 68.40 \\
\hline Lipophilicity $\left(\log \mathrm{P}_{\mathrm{o} / \mathrm{w}}\right)$ & 2.87 & 2.63 & 3.24 & 3.70 & 3.83 \\
\hline \multicolumn{6}{|l|}{ Drug-likeness } \\
\hline Lipinski & Yes; 0 violation & Yes; 0 violation & Yes; 0 violation & Yes; 0 violation & Yes; 0 violation \\
\hline Ghose & $\begin{array}{c}\text { No; } 1 \text { violation: } \mathrm{MW}> \\
480\end{array}$ & Yes & Yes & Yes & $\begin{array}{c}\text { No; } 2 \text { violations: WLOGP }>5.6, \\
\text { \#atoms }>70\end{array}$ \\
\hline Veber & Yes & Yes & Yes & Yes & No; 1 violation: Rotors > 10 \\
\hline Egan & Yes & Yes & Yes & Yes & No; 1 violation: WLOGP $>5.88$ \\
\hline Muegge & Yes & Yes & Yes & Yes & $\begin{array}{c}\text { No; } 2 \text { violations: XLOGP3 > 5, } \\
\text { Rotors }>15\end{array}$ \\
\hline \multicolumn{6}{|l|}{ Medicinal chemistry } \\
\hline PAINS & 0 alert & 0 alert & 0 alert & 0 alert & 0 alert \\
\hline Brenk & 1 alert: aldehyde & $\begin{array}{l}2 \text { alerts: aldehyde, } \\
\text { triple bond }\end{array}$ & 1 alert: imine & 1 alert: imine & $\begin{array}{c}2 \text { alerts: phosphor, quaternary } \\
\text { nitrogen }\end{array}$ \\
\hline Lead-likeness & $\begin{array}{c}\text { No; } 2 \text { violations: } \mathrm{MW}> \\
350, \text { Rotors }>7\end{array}$ & Yes & $\begin{array}{c}\text { No; } 3 \text { violations: } \\
\text { MW > 350, Rotors } \\
>7, \text { XLOGP3 > } 3.5\end{array}$ & $\begin{array}{c}\text { No; } 2 \text { violations: } \\
\text { MW > 350, } \\
\text { XLOGP3 > 3.5 }\end{array}$ & $\begin{array}{l}\text { No; } 3 \text { violations: MW > 350, } \\
\text { Rotors }>7 \text {, XLOGP3 > } 3.5\end{array}$ \\
\hline Synthetic accessibility & 3.44 & 3.00 & 3.52 & 3.25 & 4.67 \\
\hline
\end{tabular}

\#: number, TPSA: topological polar surface area, PAINS: pan-assay interference compounds, MW: molecular weight.

\subsection{In Silico Pharmacokinetics and Toxicity Prediction}

Pharmacokinetic properties and toxicity parameters were predicted for compounds $2,4,5$, and 6 and for miltefosine (Table 3). All the 1,4-disubstituted-1,2,3-triazole compounds displayed moderate water solubility, high intestinal absorption, P-glycoprotein I and II inhibition and low skin permeability, while compounds $\mathbf{4}$ and $\mathbf{6}$ were predicted as P-glycoprotein substrates, and only compound $\mathbf{4}$ showed high Caco-2 permeability. Human steady state volume of distribution (ssVD) was moderate for compound 2 and low for the other compounds, and only compound 6 was predicted to be readily distributed to the brain through the blood-brain barrier (BBB) and penetrate the central nervous system (CNS). All 1,4-disubstituted-1,2,3-triazole compounds revealed metabolization by isoform CYP3A4, but not by CYP2D6, and all the compounds exhibited the predicted inhibition of at least three isoforms of cytochrome P450, with compound $\mathbf{6}$ inhibiting four isoforms. Compound $\mathbf{6}$ presented the lowest total clearance of all, and no 1,4-disubstituted-1,2,3-triazole compound was predicted as a renal organic cation transporter 2 (OCT2) substrate. In toxicity parameters prediction, all 1,4-disubstituted-1,2,3-triazole compounds showed hepatotoxicity, high human maximum tolerated dose ( $>0.477 \mathrm{log} \mathrm{mg} / \mathrm{kg} /$ day $)$, toxicity to flathead minnows and Tetrahymena piriformis, and human ether-a-go-go (hERG) II inhibition, but not hERG I inhibition or skin sensitization. Compounds 5 and $\mathbf{6}$ presented mutagenic potential and potential carcinogenic action by Salmonella/microsome mutagenicity assay (AMES) prediction. While compound 4 exhibited the lowest oral rat acute toxicity, it also exhibited the highest value relative to the lowest dose of a compound that resulted in an observed adverse effect (LOAEL) in oral rat chronic toxicity, followed by compound 6 . 
Table 3. In silico pharmacokinetics and toxicity properties of 1,4-disubstituted-1,2,3-triazole compounds and miltefosine.

\begin{tabular}{|c|c|c|c|c|c|c|}
\hline \multirow{2}{*}{ Property } & \multirow{2}{*}{ Model Name } & \multicolumn{5}{|c|}{ Compounds } \\
\hline & & 2 & 4 & 5 & 6 & Miltefosine \\
\hline \multirow{7}{*}{ Absorption } & Water solubility $(\log \mathrm{mol} / \mathrm{L})$ & -4.143 & -4.327 & -5.487 & -5.382 & -6.149 \\
\hline & Caco-2 permeability (log Papp in $10^{-6} \mathrm{~cm} / \mathrm{s}$ ) & 0.538 & 1.178 & 0.776 & 0.516 & 1.049 \\
\hline & Intestinal absorption - human (\% Absorbed) & 95.298 & 100 & 93.529 & 92.221 & 92.021 \\
\hline & Skin Permeability $(\log \mathrm{Kp})$ & -2.735 & -2.641 & -2.739 & -2.732 & -2.721 \\
\hline & P-glycoprotein substrate & No & No & Yes & Yes & No \\
\hline & P-glycoprotein I inhibitor & Yes & Yes & Yes & Yes & Yes \\
\hline & P-glycoprotein II inhibitor & Yes & Yes & Yes & Yes & Yes \\
\hline \multirow{3}{*}{ Distribution } & Human ssVD (log L/kg) & 0.068 & -0.284 & -0.241 & -0.236 & 0.355 \\
\hline & BBB permeability (log BB) & -1.675 & 0.039 & -0.843 & 0.393 & -0.176 \\
\hline & CNS permeability (log PS) & -3.531 & -2.579 & -2.455 & -1.997 & -3.191 \\
\hline \multirow{7}{*}{ Metabolism } & CYP2D6 substrate & No & No & No & No & No \\
\hline & CYP3A4 substrate & Yes & Yes & Yes & Yes & Yes \\
\hline & CYP1A2 inhibitor & No & Yes & No & Yes & No \\
\hline & CYP2C19 inhibitor & No & Yes & Yes & Yes & No \\
\hline & CYP2C9 inhibitor & Yes & Yes & Yes & Yes & No \\
\hline & CYP2D6 inhibitor & No & No & No & No & No \\
\hline & CYP3A4 inhibitor & Yes & No & Yes & Yes & No \\
\hline \multirow{2}{*}{ Excretion } & Total Clearance $(\log \mathrm{mL} / \mathrm{min} / \mathrm{kg})$ & 0.386 & 0.35 & 0.671 & 0.199 & 1.112 \\
\hline & Renal OCT2 substrate & No & Yes & No & No & No \\
\hline \multirow{10}{*}{ Toxicity } & AMES toxicity & No & No & Yes & Yes & No \\
\hline & Human max. tolerated dose (log mg/kg/day) & 0.796 & 0.692 & 0.844 & 0.898 & 0.211 \\
\hline & hERG I inhibitor & No & No & No & No & No \\
\hline & hERG II inhibitor & Yes & Yes & Yes & Yes & Yes \\
\hline & Oral Rat Acute Toxicity LD50 (mol/kg) & 3.024 & 1.949 & 2.747 & 2.599 & 2.655 \\
\hline & $\begin{array}{l}\text { Oral Rat Chronic Toxicity LOAEL (log mg/kg } \\
\text { bw/day) }\end{array}$ & 0.653 & 1.39 & 0.462 & 0.99 & 0.233 \\
\hline & Hepatotoxicity & Yes & Yes & Yes & Yes & Yes \\
\hline & Skin Sensitization & No & No & No & No & Yes \\
\hline & T pyriformis toxicity $(\log \mu \mathrm{g} / \mathrm{L})$ & 0.285 & 0.474 & 0.294 & 0.327 & 0.311 \\
\hline & Minnow toxicity $(\log \mathrm{mM})$ & -1.708 & -1.322 & -2.1 & -3.393 & -1.839 \\
\hline
\end{tabular}

VDss: steady state volume of distribution, BBB: brain-blood barrier, CNS: central nervous system, OCT2: organic cation transporter 2, AMES: Salmonella/microsome mutagenicity assay, hERG: human ether-a-go-go gene, LOAEL: lowest dose of a compound that resulted in an observed adverse effect.

\section{Discussion}

The present study demonstrated the in vitro antileishmanial activity of 1,4-disubstituted-1,2,3-triazole compounds, its effects on the ultrastructure of the promastigote form of L. amazonensis, and described the drug-likeness, pharmacokinetic and toxicity properties of the compounds by in silico prediction.

Several authors have reported the use of different 1,2,3-triazole derivatives as potential antileishmanial agents [27-29]. According to our results on activity against promastigote forms, compounds 2, 4, 5, and $\mathbf{6}$ showed significant results. It was noted that in some of these compounds there are important pharmacophoric groups in addition to the triazole moiety, such as sulfonylhydrazone and hydrazone, also known for their antileishmanial activity [30,31]. Compound 2, which has two triazole moieties, exhibited activity against promastigotes and intracellular amastigotes of L. amazonensis.

Evaluation of the intracellular amastigote revealed that compound 6 had the best activity of the compounds analyzed. In addition to triazole, compound $\mathbf{6}$ contains another important pharmacophoric group, the arylhydrazone. Hydrazones are important groups, known for their leishmanicidal properties and presence in many compounds used as antileishmanial agents [31,32]. The arylhydrazone may be related to the greater activity exhibited by compound 6 in comparison to the other compounds analyzed.

The highest cytotoxicity against BALB/c peritoneal macrophages was exhibited by compounds $\mathbf{2}$, 4 , and 5 . This may be related to the presence of the aldehyde group in compounds 2 and 4 , and the sulfonyl group in compound $\mathbf{5}$. It is known that sufficiently electrophilic groups, such as the aldehyde and sulfonyl groups, can react with DNA [33], which may explain the toxicity displayed by these compounds. In addition, the sulphonyl hydrazine derivatives are associated with the inhibition of mammal cells enzymes [25,34], such as carbonic anhydrase, an enzyme that plays an important role in $\mathrm{pH}$ regulation [25], which may be related to the higher cytotoxicity of compound $\mathbf{5}$ and its sulfanyl moiety. Compound 6, meanwhile, had the lowest cytotoxicity, possibly associated with the presence 
of the arylhydrazone group. Several studies have described the use of hydrazone derivatives with leishmanicidal activity, reporting their good selectivity rates and low cytotoxicity [31,32,35].

The cytotoxicity result, associated with activity against intracellular amastigotes, revealed compound 6 to have the highest selectivity for parasites among the compounds, with SI even better than miltefosine. The selectivity index is an established criterion for the identification of potential compounds against infectious diseases. The Japanese Global Health Innovative Technology and the Drugs for Neglected Diseases initiative agreed that the SI of a lead compound should be greater than the 10-fold selectivity window for cytotoxicity using a mammalian cell [36]. Compound 6 falls within this criteria, and has thus been classified as a hit compound.

The transmission electron microscopy of L. amazonensis promastigotes treated with 1,4-disubstituted-1,2,3-triazole compounds revealed various alterations in the parasite ultrastructure. One remarkable change observed was the alterations in mitochondria, such as the swelling of the kinetoplast and the breakdown of mitochondrial cristae. These mitochondrial alterations were also observed in L. amazonensis promastigotes treated with a triazole hybrid of neolignanes [37] and with ravuconazole [38], a triazole antifungal drug. These ultrastructural alterations are related to dysfunctional mitochondria. It was reported that 1,2,3-triazole derivatives induce mitochondrial alteration through an increment in ROS and depolarization of the mitochondrial membrane potential of L. amazonensis promastigotes [22].

Another ultrastructural alteration described in literature that we observed in parasites treated with 1,4-disubstituted-1,2,3-triazole compounds was the presence of lipid corpuscles. These lipid inclusions were associated with vesicles with electron-dense material in the cytoplasm and near the flagellar pocket, as well as with the presence of material inside the flagellar pocket. All these alterations may be related to the alteration in lipid biosynthesis, which induces the accumulation of lipid bodies $[37,38]$ and promotes the formation of vesicles in the cytoplasm, as a consequence of drug action or the indication of the exacerbated production of proteins by cells in an attempt to survive, resulting in increased activity in the region of the exocytic flagellar pocket as a result of the abnormal secretion of lipids [39]. These alterations have also been described in other study using L. amazonensis promastigotes treated with ergosterol synthesis inhibitors [40]. Leishmania parasites produce ergosterol-related sterols by a biosynthetic pathway similar to that which operates in the pathogenic fungi, and their growth is susceptible to sterol biosynthesis inhibitors [41], a plausible mechanism of action of the triazole compounds.

Nuclear alterations, such as chromatin condensation and the discontinuity of the nuclear membrane, have already been observed and described in L. amazonensis promastigotes treated with triazole compounds [37], and were observed in parasites treated with compound $\mathbf{6}$, showing that this compound has potent antileishmanial activity in vitro.

Nitrite quantification was used to indirectly quantify nitric oxide (NO) production in BALB/c peritoneal macrophages. Although all the 1,4-disubstituted-1,2,3-triazole compounds increased nitrite levels in the peritoneal macrophage, compound $\mathbf{6}$ was able to induce NO production in macrophages infected with L. amazonensis. NO is a short-lived and freely diffusible gas that originates from the conversion of L-arginine to L-citrulline, by NO synthase (NOS) enzyme [42]. In infected host organisms, NO demonstrates antimicrobial and immunostimulatory (proinflammatory) effects, contributing to the killing of intracellular parasites like Leishmania $[43,44]$. The increase in NO production by compound 6 evidences the probability of macrophage immunomodulation as one of its effector mechanisms against intracellular amastigotes.

Further to in vitro studies, we also carried out in silico analyses. Studies using in silico methodologies are tools that can be used in drug development, giving physical-chemistry, drug-likeness, pharmacokinetic and toxicity parameters, which may be helpful for further studies. Medicinal chemistry, for example, analyzed the physicochemical structure of compounds and predicted the presence or absence of a problematic moiety, lead-likeness, and synthetic accessibility in 1,2,3-triazole [45]. 
Lipinski's rule of five is a drug-likeness parameter widely used in in silico analysis for the evaluation of physio-chemical properties that would make a compound behave as an orally active drug in humans. This rule states that molecular mass should be less than 500 Daltons, have no more than five $\mathrm{H}$-bond donors and no more than $10 \mathrm{H}$-bond acceptors, and a calculated $\log \mathrm{P}(\mathrm{CLogP})$ no greater than five (or MLogP > 4.15). Compounds that violate more than two of Lipinski's rules may encounter problems in the first step of absorption, such as poor solubility and intestinal permeability, interfering in oral bioavailability [46]. For an even more rigorous evaluation, four drug-likeness in silico predictions were performed - the Ghose (Amgen), Veber (GSK), Egan (Pharmacia), and Muegge (Bayer) methods [45].

Several specialized prediction models were also compiled with the pharmacokinetic parameters, evaluating the individual absorption, distribution, metabolization, and excretion behaviors of the compounds under investigation. The same was performed with the toxicity parameters. The pkCSM [47] and SwissADME [45] tools were used throughout the in silico study we used, comparing and complementing the results to achieve a robust outcome, targeting the desired characteristics of a new drug for leishmaniasis. Due to the low skin permeability, the 1,4-disubstituted-1,2,3-triazole compounds, in the same way as miltefosine, are not strong candidates for a topical formulation aimed at cutaneous leishmaniasis treatment. However, considering all the in silico prediction analysis, the compound (6), that presented promising antileishmanial activity in vitro, exhibited similar or even better results than miltefosine and is a good candidate for further in vivo studies against Leishmania parasites.

\section{Materials and Methods}

\subsection{Reagents}

Dimethyl sulfoxide (DMSO), Schneider's Insect medium, streptomycin, 3-(4,5-dimethylthiazol-2-yl)-2,5-diphenyltetrazolium bromide (MTT), miltefosine, Brewer thioglycollate medium, RPMI 1640, glutaraldehyde, sodium-cacodylate, EPON 812, sulfanilamide, N-(1-naphthyl) ethylenediamine, $\mathrm{H}_{3} \mathrm{PO}_{4}$, osmium tetroxide, potassium ferrocyanide, calcium chloride, uranyl acetate, lead citrate, sodium citrate and acetone were purchased from Sigma, St Louis, MO, USA. Fetal bovine sera and penicillin were purchased from Gibco, Gaithersburg, MD, USA. Giemsa's azur-eosin-methylene blue was purchased from MERK, Darmstadt, Germany.

\subsection{Triazole Compounds}

The 1,4-disubstituted-1,2,3-triazole derivatives 1-10 were previously synthesized by copper-catalyzed azide-alkyne cycloaddition reaction, as described by Silva et al. 2019 [24]. All the compounds were structurally characterized by the ${ }^{1} \mathrm{H}$ NMR, ${ }^{13} \mathrm{C}$ NMR and mass spectrometry techniques. Stock solutions were prepared in DMSO with a final concentration that never exceeded $1 \%$ DMSO, which is not toxic to either the parasite and mammalian cells.

\subsection{Parasites}

Leishmania amazonensis (MHOM/BR/76/MA-76) promastigote forms of were cultured at $26{ }^{\circ} \mathrm{C}$ in Schneider's Insect medium added with 10\% fetal bovine sera (FBS), $100 \mathrm{U} / \mathrm{mL}$ of penicillin and $100 \mu \mathrm{g} / \mathrm{mL}$ of streptomycin. Parasite cultures with a maximum of seven in vitro passages were used.

\subsection{Activity against Promastigote Forms}

L. amazonensis promastigote forms obtained from a 2-4-day-old culture were placed in 96-well plates with varied concentrations of triazole compounds obtained by serial dilutions 1:2 (300 to $1.17 \mu \mathrm{M})$, at a final volume of $100 \mu \mathrm{L}$ per well, for $72 \mathrm{~h}$. Blanks composed by wells without parasites and wells with parasites plus DMSO 1\% only were used as controls. A modified colorimetric method with tetrazolium-dye MTT was used to evaluate parasite viability [48,49]. A quantity of $10 \mu \mathrm{L}$ of 
MTT ( $5 \mathrm{mg} / \mathrm{mL}$ ) was added to each well. After five hours, $150 \mu \mathrm{L}$ of DMSO was added to each well to dissolve the formazan crystals. Absorbance was read on a spectrophotometer at a wavelength of $570 \mathrm{~nm}$. The data was normalized and the results were used to calculate the $\mathrm{IC}_{50}(50 \%$ inhibition of parasite growth). Miltefosine was used as a reference drug.

\subsection{Animals}

The local Ethics Committee on Animal Care and Utilization authorized all the procedures with animals (CEUA/IOC - L053/2016, December 28, 2016). BALB/c female mice 4-6 weeks old purchased from the Instituto de Ciência e Tecnologia em Biomodelos, Instituto Oswaldo Cruz, Rio de Janeiro were used in the study. The animals were maintained under pathogen-free conditions and handled in accordance with the National Council for Control of Animal Experimentation (Conselho Nacional de Controle de Experimentação Animal; CONCEA).

\subsection{Cell Culture}

The peritoneal macrophages were obtained from BALB/c mice elicited with $3 \mathrm{~mL}$ Brewer thioglycollate medium for $72 \mathrm{~h}$, intraperitoneal. After euthanasia, cells were obtained by peritoneal washing with PBS, centrifuged at $4000 \mathrm{rpm}$ for $5 \mathrm{~min}$, and suspended in RPMI 1640 medium plus 10\% FBS, $100 \mathrm{U} / \mathrm{mL}$ of penicillin and $100 \mu \mathrm{g} / \mathrm{mL}$ of streptomycin [50]. The cells were immediately used in experiments and maintained at $37^{\circ} \mathrm{C}$ and $5 \% \mathrm{CO}_{2}$.

\subsection{Cytotoxicity Assay}

BALB/c peritoneal macrophages were cultured in 96 -well plates $\left(5 \times 10^{5}\right.$ cells $\left./ \mathrm{mL}\right)$ with different concentrations of triazole compounds obtained by serial dilutions $1: 2(600$ to $2.34 \mu \mathrm{M})$, or miltefosine (50 to $0.19 \mu \mathrm{M}$ ) up to a final volume of $100 \mu \mathrm{L}$ per well, at $37^{\circ} \mathrm{C}$ and $5 \% \mathrm{CO}_{2}$. Blanks were composed by wells without cells and wells with cells plus $1 \%$ of DMSO only. Cell viability was carried out by the modified MTT colorimetric method as described before [51]. Tem microliters of MTT at $5 \mathrm{mg} / \mathrm{mL}$ was added to each well and incubated for two hours at $37^{\circ} \mathrm{C}$ and $5 \% \mathrm{CO}_{2}$. The plate was then centrifuged for five minutes at $1500 \mathrm{rpm}$, the supernatants were removed and the formazan crystals solubilized with $100 \mu \mathrm{L}$ of DMSO in a shaker-plate for $10 \mathrm{~min}$. The absorbance was determined in a spectrophotometer at a wavelength of $570 \mathrm{~nm}$. Cytotoxicity was demonstrated as a percentage, and the concentration inhibiting $50 \%$ of cell growth $\left(\mathrm{CC}_{50}\right)$ was calculated using the GraphPad Prism 7.00 (GraphPad Software, San Diego, CA, USA) software package.

\subsection{Activity against Intracellular Amastigote and Selectivity Index}

Activity against the intracellular amastigotes was carried out in 24-well plates with coverslips with peritoneal macrophages $\left(5 \times 10^{5}\right.$ cells/well). Cells were infected with $L$. amazonensis promastigote forms using a ratio of 10:1 parasite/cell. After $6 \mathrm{~h}$ after infection the cells were washed three times with PBS to remove non-internalized parasites. Infected cells were treated with different concentrations of triazole compounds obtained by serial dilutions 1:2 $(37.5-2.3 \mu \mathrm{M})$ or miltefosine $(25-1.56 \mu \mathrm{M})$ for $24 \mathrm{~h}$. The infected and treated cells adhered to the coverslips were fixed with Bouin, stained with Giemsa's azur-eosin-methylene blue and examined by light microscopy. The intracellular number of amastigotes of 200 cells were normalized and used to calculate the $\mathrm{IC}_{50}$. The percentage of infected cells was determined by number of infected cells divided by two. The mean number of amastigotes per cell was determined using the number of intracellular amastigotes counted in 200 cells divided by the number of infected cells. The selectivity index was calculated from the ratio of $\mathrm{CC}_{50}$ versus the $\mathrm{IC}_{50}$ for intracellular amastigotes [52]. 


\subsection{Transmission Electron Microscopy}

The promastigote forms of L. amazonensis were treated for $24 \mathrm{~h}$ with $\mathrm{IC}_{50}$ of the 1,2,3-triazole compounds which exhibited the best activity against the promastigotes. The parasites were fixed with $2.5 \%$ glutaraldehyde in a $0.1 \mathrm{M}$ sodium-cacodylate buffer, $\mathrm{pH} 7.2$ overnight. Then, parasites were washed three times with $0.1 \mathrm{M}$ sodium-cacodylate buffer, post-fixed in a solution composed by $1 \%$ osmium tetroxide, $0.8 \%$ potassium ferrocyanide, and $5 \mathrm{mM}$ calcium chloride, dehydrated in graded acetone and embedded in EPON 812. Ultrathin sections were obtained from $100 \mathrm{~nm}$ cuts in Sorvall MT 2-B (Porter Blum) ultramicrotone (Sorvall, Newtown, CT, USA) stained with 5\% uranyl acetate aqueous solution and lead citrate (1.33\% lead nitrate and $1.76 \%$ sodium citrate), and examined in a transmission electron microscope JEM-1011 (JEOL, Tokyo, Japan) operating at $80 \mathrm{kV} \mathrm{[53].}$

\subsection{Nitrite Quantification in Macrophages Stimulated with L. amazonensis and Treated with Triazoles}

BALB/c peritoneal macrophages at $5 \times 10^{6}$ cells/mL were stimulated with $L$. amazonensis promastigotes (10:1 parasites:cell) for one hour, and treated with different concentrations of triazole compounds for $48 \mathrm{~h}$. Nitrite quantification of the supernatant of the cells was performed with Griess reagent [54]. Then, $50 \mu \mathrm{L}$ of culture supernatant were added to $50 \mu \mathrm{L}$ of Griess reagent $(25 \mu \mathrm{L}$ of sulfanilamide $1 \%$ in $2.5 \% \mathrm{H}_{3} \mathrm{PO}_{4}$ solution and $25 \mu \mathrm{L}$ of $\mathrm{N}$-(1-naphthyl) ethylenediamine $0.1 \%$ solution) in 96-well plates and read after $10 \mathrm{~min}$ at $570 \mathrm{~nm}$ on the spectrophotometer. The nitrite concentrations were obtained from the standard curve of sodium nitrite $(100$ to $0.3 \mu \mathrm{M})$ [43].

\subsection{In Silico Pharmacokinetics Prediction}

The structures of 1,2,3-triazole compounds were drawn using ChemDraw software (version Ultra 12.0, PerkinElmer Informatics, Waltham, MA, USA) and were converted into a single database file SMILES. In silico physicochemical, drug-likeness, pharmacokinetics and toxicity properties were assessed with the pkCSM [47] and SwissADME [45] web tools.

\subsection{Statistical Analyses}

A nonlinear regression fit curve of concentration log versus normalized response originated the $\mathrm{IC}_{50}$ and $\mathrm{CC}_{50}$. The data were expressed as mean \pm S.D. GraphPad Prism 7.00 were used to perform the analyses and differences were considered significant when $p<0.05$.

\section{Conclusions}

The 1,4-disubstituted-1,2,3-triazole compounds were evaluated against L. amazonensis, with compound 6 exhibiting the best activity against the promastigote and intracellular amastigote forms, altering all parameters of in vitro infection. This compound also exhibited low cytotoxicity to macrophages and a high selectivity index to parasites over cells. Ultrastructural analysis showed that 1,4-disubstituted-1,2,3-triazole treatment induces mitochondrial alterations, such as swelling of the kinetoplast and the breakdown of the mitochondrial cristae, suggesting its dysfunction, and lipid bodies inclusion with an increase in exocytic activity that may be related to lipid biosynthesis inhibition. Compound 6 was able to enhance 2.3-fold the nitrite levels in the stimulated macrophage. In silico pharmacokinetics prediction analysis of compound 6 revealed that it is not recommended for topical formulation aimed at cutaneous leishmaniasis treatment. The other properties, however, exhibited results that were similar or even better than miltefosine, making it a promising candidate for further in vivo studies against Leishmania parasites. 
Author Contributions: Conceptualization, F.A.-S., A.L.A.-S., and K.d.S.C.; methodology, F.A.-S., V.D.d.S., D.d.J.H., and N.N.T.; formal analysis, F.A.-S., V.D.d.S., G.X.S., and N.N.T.; investigation, F.A.-S. and N.N.T.; resources, F.A.-S., N.N.T., C.D.B., A.L.A.-S., and K.d.S.C.; data curation, F.A.-S., N.N.T., and C.D.B.; writing-original draft preparation, F.A.-S. and V.D.d.S.; writing-review and editing, F.A.-S., N.N.T., C.D.B., A.L.A.-S., and K.d.S.C.; visualization, F.A.-S. and V.D.d.S.; supervision, F.A.-S., C.D.B., A.L.A.-S., and K.d.S.C.; project administration, F.A.-S. and C.D.B.; funding acquisition, F.A.-S., N.N.T., C.D.B., A.L.A.-S., and K.d.S.C. All authors have read and agreed to the published version of the manuscript.

Funding: This research was funded by the Coordination for the Improvement of Higher Education Personnel (Coordenação de Aperfeiçoamento de Pessoal de Nível Superior do Brazil; CAPES) grant number Finance Code 001; and the Carlos Chagas Filho Foundation for Research Support of the State of Rio de Janeiro (Fundação Carlos Chagas Filho de Amparo à Pesquisa do Estado do Rio de Janeiro; FAPERJ) grant number E-26/010.001759/2019. The APC was funded by the Oswaldo Cruz Institute (Instituto Oswaldo Cruz; IOC). Dr. Fernando Almeida-Souza is a postdoctoral researcher fellow of CAPES grant number 88887.363006/2019-00. Dra. Ana Lucia Abreu-Silva is a research productivity fellow of National Scientific and Technological Development Council (Conselho Nacional de Desenvolvimento Científico e Tecnológico; CNPq) grant number 309885/2017-5.

Conflicts of Interest: The authors declare no conflict of interest.

\section{Abbreviations}

$\begin{array}{ll}\text { WHO } & \text { World Health Organization } \\ \text { IC }_{50} & \text { inhibitory concentration of } 50 \% \\ \text { CC }_{50} & \text { cytotoxicity concentration of } 50 \% \\ \text { SI } & \text { selectivity index } \\ \text { TPSA } & \text { topological polar surface area } \\ \text { PAINS } & \text { pan-assay interference compounds } \\ \text { VDss } & \text { steady state volume of distribution } \\ \text { CNS } & \text { central nervous system } \\ \text { BBB } & \text { blood-brain barrier } \\ \text { hERG } & \text { human ether-a-go-go gene } \\ \text { AMES } & \text { Salmonella/microsome mutagenicity assay } \\ \text { LOAEL } & \text { lowest dose of a compound that results in an observed adverse effect } \\ \text { OCT2 } & \text { organic cation transporter 2, } \\ \text { DMSO } & \text { dimethyl sulfoxide } \\ \text { MTT } & \text { 3-(4,5-dimethylthiazol-2-yl)-2,5-diphenyltetrazolium bromide }\end{array}$

\section{References}

1. Murray, H.W.; Berman, J.D.; Davies, C.R.; Saravia, N.G. Advances in leishmaniasis. Lancet 2005, 366, 1561-1577. [CrossRef]

2. Yeshaw, Y.; Tsegaye, A.T.; Nigatu, S.G. Incidence of Mortality and Its Predictors Among Adult Visceral Leishmaniasis Patients at the University of Gondar Hospital: A Retrospective Cohort Study. Infect. Drug Resist. 2020, 13. [CrossRef] [PubMed]

3. Alvar, J.; Vélez, I.D.; Bern, C.; Herrero, M.; Desjeux, P.; Cano, J.; Jannin, J.; den Boer, M.; Team, W.L.C. Leishmaniasis worldwide and global estimates of its incidence. PLoS ONE 2012, 7, e35671. [CrossRef] [PubMed]

4. WHO. WHO Epidemiological Situation. Available online: https://www.who.int/leishmaniasis/burden/en/ (accessed on 5 June 2020).

5. Lanza, J.S.; Pomel, S.; Loiseau, P.M.; Frézard, F. Recent Advances in Amphotericin B Delivery Strategies for the Treatment of Leishmaniases. Expert Opin. Drug Deliv. 2019, 16. [CrossRef] [PubMed]

6. Uliana, S.R.; Trinconi, C.T.; Coelho, A.C. Chemotherapy of leishmaniasis: Present challenges. Parasitology 2017, 1-17. [CrossRef] [PubMed]

7. Khatri, A.; Sah, R.; Timalsena, S.; Kharel, M. Miltefosine-related Paracentral Ulcerative Keratolysis in a Patient with Active Cutaneous Leishmaniasis From Nepal. Trop. Dr. 2020. [CrossRef]

8. Oliveira, L.F.; Schubach, A.O.; Martins, M.M.; Passos, S.L.; Oliveira, R.V.; Marzochi, M.C.; Andrade, C.A. Systematic Review of the Adverse Effects of Cutaneous Leishmaniasis Treatment in the New World. Acta Trop. 2011, 118. [CrossRef] 
9. Aronson, N.E. Addressing a clinical challenge: Guidelines for the diagnosis and treatment of leishmaniasis. BMC Med. 2017, 15, 76. [CrossRef]

10. Corrêa Soares, G.H.; Santos da Silva, A.B.; Salomão de Sousa Ferreira, L.; Ithamar, J.S.; de Alencar Medeiros, G.; Ferreira Pereira, S.R.; Sousa Lima, M.I.; de Maria Pedrozo E Silva de Azevedo, C. Case Report: Coinfection by Leishmania amazonensis and HIV in a Brazilian Diffuse Cutaneous Leishmaniasis Patient. Am. J. Trop. Med. Hyg. 2020. [CrossRef]

11. Dheer, D.; Singh, V.; Shankar, R. Medicinal Attributes of 1,2,3-triazoles: Current Developments. Bioorg. Chem. 2017, 71. [CrossRef]

12. Kolb, H.C.; Sharpless, K.B. The Growing Impact of Click Chemistry on Drug Discovery. Drug Discov. Today 2003, 8. [CrossRef]

13. Bonandi, E.; Christodoulou, M.S.; Fumagalli, G.; Perdicchia, D.; Rastelli, G.; Passarella, D. The 1,2,3-triazole Ring as a Bioisostere in Medicinal Chemistry. Drug Discov. Today 2017, 22. [CrossRef] [PubMed]

14. Boechat, N.; Ferreira, V.F.; Ferreira, S.B.; de Lourdes G Ferreira, M.; de C da Silva, F.; Bastos, M.M.; Dos S Costa, M.; Lourenço, M.C.; Pinto, A.C.; Krettli, A.U.; et al. Novel 1,2,3-triazole Derivatives for Use Against Mycobacterium Tuberculosis H37Rv (ATCC 27294) Strain. J. Med. Chem. 2011, 54. [CrossRef]

15. Mady, M.F.; Awad, G.E.; Jørgensen, K.B. Ultrasound-assisted Synthesis of Novel 1,2,3-triazoles Coupled Diaryl Sulfone Moieties by the CuAAC Reaction, and Biological Evaluation of Them as Antioxidant and Antimicrobial Agents. Eur. J. Med. Chem. 2014, 84. [CrossRef] [PubMed]

16. Song, M.X.; Deng, X.Q. Recent Developments on Triazole Nucleus in Anticonvulsant Compounds: A Review. J. Enzym. Inhib. Med. Chem. 2018, 33. [CrossRef]

17. Mohammed, I.; Kummetha, I.R.; Singh, G.; Sharova, N.; Lichinchi, G.; Dang, J.; Stevenson, M.; Rana, T.M. 1,2,3-Triazoles as Amide Bioisosteres: Discovery of a New Class of Potent HIV-1 Vif Antagonists. J. Med. Chem. 2016, 59. [CrossRef]

18. Yadav, P.; Lal, K.; Kumar, A.; Guru, S.K.; Jaglan, S.; Bhushan, S. Green Synthesis and Anticancer Potential of Chalcone linked-1,2,3-triazoles. Eur. J. Med. Chem. 2017, 126. [CrossRef]

19. Tornøe, C.W.; Christensen, C.; Meldal, M. Peptidotriazoles on Solid Phase: [1,2,3]-triazoles by Regiospecific Copper(i)-Catalyzed 1,3-dipolar Cycloadditions of Terminal Alkynes to Azides. J. Org. Chem. 2002, 67. [CrossRef] [PubMed]

20. Kolb, H.C.; Finn, M.G.; Sharpless, K.B. Click Chemistry: Diverse Chemical Function From a Few Good Reactions. Angew. Chem. 2001, 40. [CrossRef]

21. Chen, Y.; Yao, K.; Wang, K.; Xiao, C.; Li, K.; Khan, B.; Zhao, S.; Yan, W.; Ye, Y. Bioactive-guided Structural Optimization of 1,2,3-triazole Phenylhydrazones as Potential Fungicides Against Fusarium Graminearum. Pestic. Biochem. Physiol. 2020, 164. [CrossRef]

22. Meinel, R.S.; Almeida, A.D.C.; Stroppa, P.H.F.; Glanzmann, N.; Coimbra, E.S.; da Silva, A.D. Novel Functionalized 1,2,3-triazole Derivatives Exhibit Antileishmanial Activity, Increase in Total and mitochondrial-ROS and Depolarization of Mitochondrial Membrane Potential of Leishmania amazonensis. Chem. Biol. Interact. 2020, 315. [CrossRef]

23. Stroppa, P.H.F.; Antinarelli, L.M.R.; Carmo, A.M.L.; Gameiro, J.; Coimbra, E.S.; da Silva, A.D. Effect of 1,2,3-triazole Salts, Non-Classical Bioisosteres of Miltefosine, on Leishmania amazonensis. Bioorgan. Med. Chem. 2017, 25. [CrossRef] [PubMed]

24. Da Silva, V.D.; de Faria, B.M.; Colombo, E.; Ascari, L.; Freitas, G.P.A.; Flores, L.S.; Cordeiro, Y.; Romão, L.; Buarque, C.D. Design, Synthesis, Structural Characterization and in Vitro Evaluation of New 1,4-disubstituted-1,2,3-triazole Derivatives Against Glioblastoma Cells. Bioorgan. Chem. 2019, 83. [CrossRef]

25. Queen, A.; Khan, P.; Idrees, D.; Azam, A.; Hassan, M.I. Biological Evaluation of P-Toluene Sulphonylhydrazone as Carbonic Anhydrase IX Inhibitors: An Approach to Fight Hypoxia-Induced Tumors. Int. J. Biol. Macromol. 2018, 106. [CrossRef] [PubMed]

26. Sangshetti, J.N.; Kalam Khan, F.A.; Kulkarni, A.A.; Aroteb, R.; Patilc, R.H. Antileishmanial drug discovery: Comprehensive review of the last 10 years. RSC Adv. 2015, 32376-32415. [CrossRef]

27. Maji, K.; Abbasi, M.; Podder, D.; Datta, R.; Haldar, D. Potential Antileishmanial Activity of a Triazole-Based Hybrid Peptide against Leishmania major. ChemistrySelect 2018, 3, 10220-10225. [CrossRef] 
28. Rodrigues, M.P.; Tomaz, D.C.; Ângelo de Souza, L.; Onofre, T.S.; Aquiles de Menezes, W.; Almeida-Silva, J.; Suarez-Fontes, A.M.; Rogéria de Almeida, M.; Manoel da Silva, A.; Bressan, G.C. Synthesis of Cinnamic Acid Derivatives and Leishmanicidal Activity Against Leishmania Braziliensis. Eur. J. Med. Chem. 2019, 183. [CrossRef] [PubMed]

29. Temraz, M.G.; Elzahhar, P.A.; El-Din A Bekhit, A.; Bekhit, A.A.; Labib, H.F.; Belal, A.S.F. Anti-leishmanial Click Modifiable Thiosemicarbazones: Design, Synthesis, Biological Evaluation and in Silico Studies. Eur. J. Med. Chem. 2018, 151. [CrossRef]

30. Zhao, C.; Rakesh, K.P.; Ravidar, L.; Fang, W.Y.; Qin, H.L. Pharmaceutical and Medicinal Significance of Sulfur (S VI)-Containing Motifs for Drug Discovery: A Critical Review. Eur. J. Med. Chem. 2019, 162. [CrossRef]

31. Coimbra, E.S.; Antinarelli, L.M.R.; de A Crispi, M.; Nogueira, T.C.M.; Pinheiro, A.C.; de Souza, M.V.N. Synthesis, Biological Activity, and Mechanism of Action of 2-Pyrazyl and Pyridylhydrazone Derivatives, New Classes of Antileishmanial Agents. ChemMedChem 2018, 13. [CrossRef]

32. da Silva, E.T.; de Andrade, G.F.; Araújo, A.D.S.; Almeida, A.D.C.; Coimbra, E.S.; de Souza, M.V.N. In Vitro Assessment of Camphor Hydrazone Derivatives as an Agent Against Leishmania amazonensis. Acta Parasitol. 2020, 65. [CrossRef] [PubMed]

33. Enoch, S.J.; Ellison, C.M.; Schultz, T.W.; Cronin, M.T. A Review of the Electrophilic Reaction Chemistry Involved in Covalent Protein Binding Relevant to Toxicity. Crit. Rev. Toxicol. 2011, 41. [CrossRef] [PubMed]

34. Oliveira, R.G.; Guerra, F.S.; Mermelstein, C.D.S.; Fernandes, P.D.; Bastos, I.T.S.; Costa, F.N.; Barroso, R.C.R.; Ferreira, F.F.; Fraga, C.A.M. Synthesis and Pharmacological Evaluation of Novel Isoquinoline N-sulphonylhydrazones Designed as ROCK Inhibitors. J. Enzym. Inhib. Med. Chem. 2018, 33. [CrossRef] [PubMed]

35. Vargas, E.; Echeverri, F.; Upegui, Y.A.; Robledo, S.M.; Quiñones, W. Hydrazone Derivatives Enhance Antileishmanial Activity of Thiochroman-4-ones. Molecules 2017, 23, 70. [CrossRef] [PubMed]

36. Katsuno, K.; Burrows, J.N.; Duncan, K.; Hooft van Huijsduijnen, R.; Kaneko, T.; Kita, K.; Mowbray, C.E.; Schmatz, D.; Warner, P.; Slingsby, B.T. Hit and lead criteria in drug discovery for infectious diseases of the developing world. Nat. Rev. Drug Discov. 2015, 14, 751-758. [CrossRef]

37. Cardozo Pinto de Arruda, C.; de Jesus Hardoim, D.; Silva Rizk, Y.; da Silva Freitas de Souza, C.; Zaverucha do Valle, T.; Bento Carvalho, D.; Nosomi Taniwaki, N.; de Morais Baroni, A.C.; da Silva Calabrese, K. A Triazole Hybrid of Neolignans as a Potential Antileishmanial Agent by Triggering Mitochondrial Dysfunction. Molecules 2019, 25, 37. [CrossRef]

38. Teixeira de Macedo Silva, S.; Visbal, G.; Lima Prado Godinho, J.; Urbina, J.A.; de Souza, W.; Cola Fernandes Rodrigues, J. In Vitro Antileishmanial Activity of Ravuconazole, a Triazole Antifungal Drug, as a Potential Treatment for Leishmaniasis. J. Antimicrob. Chemother. 2018, 73. [CrossRef]

39. Almeida-Souza, F.; Taniwaki, N.N.; Amaral, A.C.; da Silva Freitas de Souza, C.; da Silva Calabrese, K.; Abreu-Silva, A.L. Ultrastructural Changes and Death of Leishmania infantum Promastigotes Induced by Morinda citrifolia Linn. Fruit (Noni) Juice Treatment. Evid. Based Complement. Alternat. Med. 2016, 2016, 5063540. [CrossRef]

40. Rodrigues, J.C.; Attias, M.; Rodriguez, C.; Urbina, J.A.; Souza, W. Ultrastructural and biochemical alterations induced by 22,26-azasterol, a delta(24(25))-sterol methyltransferase inhibitor, on promastigote and amastigote forms of Leishmania amazonensis. Antimicrob. Agents Chemother. 2002, 46, 487-499. [CrossRef]

41. Roberts, C.W.; McLeod, R.; Rice, D.W.; Ginger, M.; Chance, M.L.; Goad, L.J. Fatty Acid and Sterol Metabolism: Potential Antimicrobial Targets in Apicomplexan and Trypanosomatid Parasitic Protozoa. Mol. Biochem. Parasitol. 2003, 126. [CrossRef]

42. Bredt, D.S. Endogenous Nitric Oxide Synthesis: Biological Functions and Pathophysiology. Free Radic. Res. 1999, 31. [CrossRef] [PubMed]

43. Almeida-Souza, F.; da Silva Freitas de Souza, C.; Taniwaki, N.N.; Silva, J.J.; de Oliveira, R.M.; Abreu-Silva, A.L.; Calabrese, K. Morinda citrifolia Linn. fruit (Noni) juice induces an increase in NO production and death of Leishmania amazonensis amastigotes in peritoneal macrophages from BALB/c. Nitric Oxide 2016, 58, 51-58. [CrossRef]

44. Bogdan, C. Nitric Oxide Synthase in Innate and Adaptive Immunity: An Update. Trends Immunol. 2015, 36. [CrossRef] [PubMed]

45. Daina, A.; Michielin, O.; Zoete, V. SwissADME: A Free Web Tool to Evaluate Pharmacokinetics, Drug-Likeness and Medicinal Chemistry Friendliness of Small Molecules. Sci. Rep. 2017, 7. [CrossRef] [PubMed] 
46. Lipinski, C.A.; Lombardo, F.; Dominy, B.W.; Feeney, P.J. Experimental and Computational Approaches to Estimate Solubility and Permeability in Drug Discovery and Development Settings. Adv. Drug Deliv. Rev. 2001, 46. [CrossRef]

47. Pires, D.E.; Blundell, T.L.; Ascher, D.B. pkCSM: Predicting Small-Molecule Pharmacokinetic and Toxicity Properties Using Graph-Based Signatures. J. Med. Chem. 2015, 58. [CrossRef] [PubMed]

48. Mosmann, T. Rapid colorimetric assay for cellular growth and survival: Application to proliferation and cytotoxicity assays. J. Immunol. Methods 1983, 65, 55-63. [CrossRef]

49. Teles, A.M.; Rosa, T.; Mouchrek, A.N.; Abreu-Silva, A.L.; Calabrese, K.D.S.; Almeida-Souza, F. Cinnamomum zeylanicum, Origanum vulgare, and Curcuma longa Essential Oils: Chemical Composition, Antimicrobial and Antileishmanial Activity. Evid. Based Complement. Alternat. Med. 2019, 2019, 2421695. [CrossRef]

50. Almeida-Souza, F.; de Oliveira, A.E.R.; Abreu-Silva, A.L.; da Silva Calabrese, K. In vitro activity of Morinda citrifolia Linn. fruit juice against the axenic amastigote form of Leishmania amazonensis and its hydrogen peroxide induction capacity in BALB/c peritoneal macrophages. BMC Res. Notes 2018, 11, 492. [CrossRef]

51. Oliveira, I.S.S.; Colares, A.V.; Cardoso, F.O.; Tellis, C.J.M.; Chagas, M.S.S.; Behrens, M.D.; Calabrese, K.S.; Almeida-Souza, F.; Abreu-Silva, A.L. Vernonia Polysphaera Baker: Anti-inflammatory Activity in Vivo and Inhibitory Effect in LPS-stimulated RAW 264.7 Cells. PLoS ONE 2019, 14. [CrossRef]

52. Oliveira, I.; Moragas Tellis, C.J.; Chagas, M.; Behrens, M.D.; Calabrese, K.D.S.; Abreu-Silva, A.L.; Almeida-Souza, F. Carapa guianensis Aublet (Andiroba) Seed Oil: Chemical Composition and Antileishmanial Activity of Limonoid-Rich Fractions. Biomed. Res. Int 2018, 2018, 5032816. [CrossRef] [PubMed]

53. Da Silva, V.D.; Almeida-Souza, F.; Teles, A.M.; Neto, P.A.; Mondego-Oliveira, R.; Mendes Filho, N.E.; Taniwaki, N.N.; Abreu-Silva, A.L.; Calabrese, K.d.S.; Mouchrek Filho, V.E. Chemical composition of Ocimum canum Sims. essential oil and the antimicrobial, antiprotozoal and ultrastructural alterations it induces in Leishmania amazonensis promastigotes. Ind. Crops Prod. 2018, 119, 201-208. [CrossRef]

54. Green, L.C.; Wagner, D.A.; Glogowski, J.; Skipper, P.L.; Wishnok, J.S.; Tannenbaum, S.R. Analysis of nitrate, nitrite, and [15N]nitrate in biological fluids. Anal. Biochem. 1982, 126, 131-138. [CrossRef]

(C) 2020 by the authors. Licensee MDPI, Basel, Switzerland. This article is an open access article distributed under the terms and conditions of the Creative Commons Attribution (CC BY) license (http://creativecommons.org/licenses/by/4.0/). 